\title{
Microbial composition of sweetness- enhanced yoghurt during fermentation and storage
}

\author{
Giuseppina Luzzi ${ }^{1}$, Erik Brinks ${ }^{1}$, Jan Fritsche ${ }^{2}$ and Charles M. A. P. Franz ${ }^{1 *}$
}

\begin{abstract}
The reformulation of dairy products to contain less added sugar can contribute to reducing sugar consumption, thereby reducing the risk of non-communicable diseases. The objective of this study was to investigate the microbial ecology of reformulated yoghurt, which was produced using bi-enzymatic modification of lactose to increase its sweetness by a factor of $2-3$. Ultimately, this reformulation strategy could reduce the amount of added sugar needed for equal sweetness of the end product. The bi-enzymatic modification relied on utilisation of a $\beta$-galactosidase enzyme to convert the milk sugar lactose to galactose and glucose, followed by the enzymatic conversion of the glucose moiety to fructose using a glucose isomerase. The microbial ecology of reformulated yoghurt produced with two mixed starter culture preparations containing either Streptococcus (S.) thermophilus and Lactobacillus (Lb.) delbrueckii or S. thermophilus, Lb. acidophilus and Bifidobacterium sp. strains, was analysed during fermentation and cool storage using $16 \mathrm{~S}$ rRNA based metagenomics. None of the yoghurt samples showed a significant difference in microbial composition between sweetness-enhanced and regular milk at all sampling time points during manufacture and storage of yoghurt. However, a significant difference between the microbiota of inoculated milk before and after fermentation was observed. In both types of yoghurt, the starter culture genera dominated the microbial ecology at the end of fermentation as expected, reducing the possibility of growth of potentially pathogenic or spoilage bacteria possibly resulting from a changed carbohydrate spectrum.
\end{abstract}

Keywords: Yoghurt, Dairy microbiota, Metagenomics, Fermentation, Reformulation, Sweetness enhancement

\section{Introduction}

Sugar is vital for the healthy functioning of the human body, yet its excess consumption should be minimised in order to reduce the risk of non-communicable diseases such as diabetes mellitus type II. In Germany, dairy products contribute to the daily added sugar consumption by 7-9\% (Alexy et al. 2003; Max Rubner-Institut 2008; Max Rubner-Institut 2016). Hence, the reformulation of fermented dairy products to contain less added sugar can contribute to reducing sugar intake in the population.

\footnotetext{
*Correspondence: charles.franz@mri.bund.de

1 Department of Microbiology and Biotechnology, Max Rubner-Institut, Hermann-Weigmann-Str. 1, 24103 Kiel, Germany

Full list of author information is available at the end of the article
}

Yoghurt and sweetened dairy products can contain up to $22 \%(\mathrm{w} / \mathrm{w})$ total sugar (Max Rubner-Institut 2016). The natural milk sugar lactose is present in these products at about $4-6 \%$, however, this sugar is not perceived as sweet (Chandan 2006). One approach to reformulate sweetened dairy products is to increase the sweetening power of lactose by converting this disaccharide into its sweeter monosaccharide components using a $\beta$-galactosidase enzyme to yield galactose and glucose (Harju et al. 2012). A further enzymatic process can then be applied, in a bienzymatic process proposed by Lorenzen et al. (2013), to convert roughly half of this glucose into the even sweeter sugar fructose, through implementation of a glucose isomerase enzyme. As the individual monosaccharide components are sweeter than lactose, the overall sweetness of lactose can be increased by a factor of $2-3$.
Springer Open

(c) The Author(s) 2020. This article is licensed under a Creative Commons Attribution 4.0 International License, which permits use, sharing, adaptation, distribution and reproduction in any medium or format, as long as you give appropriate credit to the original author(s) and the source, provide a link to the Creative Commons licence, and indicate if changes were made. The images or other third party material in this article are included in the article's Creative Commons licence, unless indicated otherwise in a credit line to the material. If material is not included in the article's Creative Commons licence and your intended use is not permitted by statutory regulation or exceeds the permitted use, you will need to obtain permission directly from the copyright holder. To view a copy of this licence, visit http://creativeco mmons.org/licenses/by/4.0/. 
Enzymatically sweetened milk can be used for the production of dairy products to increase the overall sweetness, so that products such as flavoured yoghurt or pudding can be manufactured with less added sugar when compared to the original product. In a technological and sensory study run in parallel to the current study, Luzzi et al. (2020) demonstrated that a $10-20 \%$ reduction in added sugar was possible in yoghurt and pudding samples when applying a bi-enzymatic conversion of lactose, whilst retaining comparable sensory characteristics of the final product. Luzzi et al. (2020) compared the microbial growth and acidification progression of commercial yoghurt starter culture bacteria in enzymatically-sweetened milk to that in regular milk using traditional, culture-dependent methods. It was found that starter bacteria behaved similarly in both the sweetnessenhanced and the regular milk, with starter Streptococcus (S.) sp. strains growing rapidly to $10^{9} \mathrm{cfu} / \mathrm{mL}$ and starter Lactobacillus $\left(L b\right.$.) sp. strains growing to $10^{6} \mathrm{cfu} / \mathrm{mL}$ during fermentation in both a traditional and a probiotic yoghurt culture, thus effectively reducing the $\mathrm{pH}$ to ca. 4.5 in both sweetness-enhanced and regular yoghurt. The bacterial count of Bifidobacterium species in the probiotic yoghurt after fermentation was determined to be ca. $10^{6} \mathrm{cfu} / \mathrm{mL}$.

Considering the comparable fermentation properties of two different yoghurt cultures in reformulated, sweetness-enhanced milk compared with regular milk as demonstrated by Luzzi et al. (2020), the current study analysed the exact microbial ecology of the same reformulated yoghurt samples using 16S rRNA metagenomic analyses. The aim of this study therefore was to determine whether the changes in the fermentable sugar spectrum would affect the microbial composition of the yoghurt fermentation with respect to the starter cultures or milk autochthonous microbiota.

\section{Materials and methods}

Preparation of sweetness-enhanced yoghurt and sampling Raw cow's milk for all experiments was obtained from the experimental farm (Schädtbek, Germany) of the Max Rubner-Institut in Kiel where a herd of almost 100 dairy cows is kept. Sweetness-enhanced milk for yoghurt production was prepared using the bi-enzymatic system of lactose conversion described by Lorenzen et al. (2013). In a concurrent study, the carbohydrate composition of the regular and sweetness-enhanced milk samples used for yoghurt production were analysed and reported (Luzzi et al. 2020). Yoghurt samples were produced with bi-enzymatically modified as well as regular milk as outlined by Luzzi et al. (2020). The two multi-strain starter culture preparations YoFlex ${ }^{\circledR}$ Premium 4.0 and ABT-100 from Chr. Hansen (Nienburg, Germany) were used for yoghurt production. According to the manufacturer, the traditional YoFlex ${ }^{\circledR}$ Premium 4.0 yoghurt culture contained S. thermophilus and Lb. delbrueckii subsp. bulgaricus strains. The probiotic ABT-100, as indicated in the product data sheet, was comprised of S. thermophilus, Lb. acidophilus and a Bifidobacterium species, which was not specified to species level by the manufacturer (Chr. Hansen, Nienburg, Germany).

Three independent repetitions of each yoghurt production experiment were performed. Yoghurt samples were taken at four time points per experiment: immediately after the pasteurised yoghurt milk was inoculated with starter cultures, after fermentation (at the time point of cold storage when the yoghurt $\mathrm{pH}$ had reached 4.5) as well as after five and 21 days of storage at $4{ }^{\circ} \mathrm{C}$. Sample sizes were $20 \mathrm{~mL}$ for inoculated milk and $20 \mathrm{~g}$ for yoghurt samples.

\section{Genomic DNA isolation}

In preparation for DNA isolation, inoculated milk samples $(20 \mathrm{~mL})$ were centrifuged twice for $30 \mathrm{~min}$ at $6000 \times g$ at $10{ }^{\circ} \mathrm{C}$ in a Heraeus Multifuge (Thermo Fisher Scientific, Waltham, USA; Rotor: 75002005). The final supernatant (ca. $20 \mathrm{~mL}$ ) from inoculated milk samples was stored at $-20{ }^{\circ} \mathrm{C}$ until further processing. Yoghurt samples $(20 \mathrm{~g})$ were mixed with $20 \mathrm{~mL}$ of $1 \mathrm{M}$ Tris- $\mathrm{HCl}(\mathrm{pH}$ 7.5; Carl Roth, Karlsruhe, Germany) and centrifuged twice for $20 \mathrm{~min}$ at $300 \times \mathrm{g}$ at $10^{\circ} \mathrm{C}$ in a Heraeus Multifuge. The final supernatant (ca. $40-45 \mathrm{~mL}$ ) from yoghurt samples was also stored at $-20^{\circ} \mathrm{C}$ until further analyses.

For further analyses, inoculated milk and yoghurt samples were thawed at room temperature. Bacterial cell lysis was performed using a lysis buffer comprised of $500 \mathrm{mM}$ $\mathrm{NaCl}, 50 \mathrm{mM}$ Tris- $\mathrm{HCl}$ (pH 8.0), $50 \mathrm{mM}$ EDTA and 4\% sodium dodecyl sulphate (buffer components from VWR International GmbH, Darmstadt, Germany). One volume of lysis buffer was added to all samples and these were mixed using an Intelli-Mixer RM-2M (ELMI, Calabasas, CA, USA) in the U2-mode at $80 \mathrm{rpm}$ for $10 \mathrm{~min}$. Following incubation in a $70{ }^{\circ} \mathrm{C}$ water bath (Julabo $\mathrm{GmbH}$, Seelbach, Germany) for 20 min with shaking at $196 \mathrm{rpm}$, samples were centrifuged at $4{ }^{\circ} \mathrm{C}$ for $30 \mathrm{~min}$ at $6000 \times g$ in a Heraeus Multifuge. The fat layer that formed on top of the samples was removed with a sterile pipette tip and discarded, whilst the supernatant was transferred to a fresh $50 \mathrm{~mL}$ Falcon ${ }^{\circledR}$ tube. This centrifugation step was repeated twice to obtain a clear lysate.

To each lysate tube, $10 \mathrm{M}$ ammonium acetate (Merck, Darmstadt, Germany) amounting to $10 \%$ of the total sample volume was added. Samples were briefly mixed and incubated on ice for $20 \mathrm{~min}$, before centrifuging at $4{ }^{\circ} \mathrm{C}$ for $30 \mathrm{~min}$ at $6000 \times \mathrm{g}$. One volume of 2-propanol (Carl Roth, Karlsruhe, Germany; pre-cooled to $4{ }^{\circ} \mathrm{C}$ ) was 
added to the supernatant to precipitate the DNA. Samples were mixed and incubated on ice for $45 \mathrm{~min}$, before centrifugation at $4{ }^{\circ} \mathrm{C}$ for $30 \mathrm{~min}$ at $6000 \times g$ and removal of the supernatant. Nucleic acid pellets were resuspended in $1 \mathrm{~mL}$ of 70\% HPLC gradient grade ethanol (Carl Roth, Karlsruhe, Germany) and centrifuged at 13,000 rpm for $15 \mathrm{~min}$ at $4{ }^{\circ} \mathrm{C}$ in a Heraeus Fresco21 centrifuge (Thermo Fisher Scientific, Waltham, MA, USA), air-dried and resuspended in $200 \mu \mathrm{L} 10 \mathrm{mM}$ Tris- $\mathrm{HCl}$ (pH 8.0).

To each sample, $4 \mu \mathrm{L}$ of DNAse-free RNase $(10 \mathrm{mg} / \mathrm{mL}$; VWR International GmbH, Darmstadt, Germany) was added and samples were incubated at $37^{\circ} \mathrm{C}$ for $15 \mathrm{~min}$. Thereafter, $30 \mu \mathrm{L}$ of proteinase $\mathrm{K}$ solution $(20 \mathrm{mg} / \mathrm{mL}$; AppliChem GmbH, Darmstadt, Germany) and $200 \mu \mathrm{L}$ of 'Buffer AL' from the QIAamp DNA Stool Mini Kit (QIAGEN GmbH, Hilden, Germany) were added to wash the sample and the mixture was incubated at $70{ }^{\circ} \mathrm{C}$ for $10 \mathrm{~min}$. Two volumes of 99\% HPLC gradient grade ethanol were added and samples were mixed thoroughly, prior to being transferred to the QIAamp Mini spin columns from the QIAamp DNA Stool Mini Kit (QIAGEN GmbH, Hilden, Germany) and centrifuged at $10,000 \mathrm{rpm}$ for $1 \mathrm{~min}$ at room temperature. Subsequent washing steps with Buffers 'AW1' and 'AW2' were done with $500 \mu \mathrm{L}$ of each wash buffer. Samples were eluted in $2 \times 50 \mu \mathrm{L}$ of pre-warmed 'Buffer AE' with centrifugation at $6000 \mathrm{rpm}$ for $1 \mathrm{~min}$ to maximise the eluted DNA. The DNA concentration was measured using a Qubit ${ }^{\circledR} 3.0$ Fluorometer in conjunction with the Qubit ${ }^{\mathrm{TM}}$ dsDNA BR Assay Kit following the manufacturer's protocol (Thermo Fisher Scientific, Darmstadt, Germany).

\section{Library preparation and sequencing}

The bacterial community composition was determined using tag-encoded, MiSeq ${ }^{\mathrm{TM}}$ System-based 16S rRNA gene high throughput sequencing. The genomic DNA was diluted to $1.67 \mathrm{ng} / \mu \mathrm{L}$ prior to library preparation. Specific primers for the 16S rRNA gene V3 and V4 regions with Illumina adapter overhangs were used for amplification of the bacterial community in all samples (16S fw-meta 5'-TCG TCG GCA GCG TCA GAT GTG TAT AAG AGA CAG CCT ACG GGN GGC WGC AG- $3^{\prime}$ and $16 \mathrm{~S}$ rev-meta $5^{\prime}$-GCT TCG TGG GCT CGG AGA TGT GTA TAA GAG ACA GGA CTA CHV GGG TAT CTA ATC C-3') (Klindworth et al. 2013). DNA amplification was carried out following the two-stage PCR protocol for 16S Metagenomic Sequencing Library Preparation provided by Illumina (Illumina Inc., San Diego, CA, USA). The size of the 16S rRNA gene PCR products was confirmed by means of automated electrophoresis using the Experion ${ }^{\mathrm{TM}}$ Automated Electrophoresis System in conjunction with the Experion ${ }^{\mathrm{TM}}$ DNA $12 \mathrm{~K}$ Assay Kit according to the manufacturer's instructions
(Bio-Rad Laboratories, Inc., CA, USA). 16S rRNA gene sequencing was performed on a MiSeq ${ }^{\mathrm{TM}}$ System using the MiSeq Reagent Kit v3 following the manufacturer's instructions (Illumina Inc., San Diego, CA, USA). Samples with a sequencing coverage of $<10 \mathrm{~K}$ reads were resequenced and the reads from both runs were combined for subsequent analyses.

\section{Data analysis}

The raw dataset was analysed using the de novo analysis pipeline of the IMNGS platform for ecology and diversity studies of the Technical University of Munich (Lagkouvardos et al. 2016). The raw fastq files were pre-processed using the Remultiplexor Perl script available through the IMNGS platform and then uploaded to the IMNGS pipeline, which implements the UPARSE algorithm from the USEARCH 8 (32-bit) package (Edgar 2010, 2013). The pipeline produced operational taxonomic unit (OTU) tables for each sample, which were uploaded to the SINA Arb Silva Aligner to compare these with both the Silva and rdp reference databases (Pruesse et al. 2012; Cole et al. 2014). The consolidated and verified OTU tables were used for statistical analysis using RStudio Version 1.1.423 by implementing the set of 'Rhea scripts' published by Lagkouvardos et al. (2017). These R scripts were used for $16 \mathrm{~S}$ rRNA gene bioinformatic analysis of yoghurt samples by processing the OTU tables. Taxonomic binning to visualise the taxonomic composition of samples was performed in Microsoft Excel using the OTU tables generated by the Rhea pipeline. For statistical analysis, the Rhea pipeline applied a permutational multivariate analysis of variance (PERMANOVA) using distance matrices (vegan::adonis) to calculate the significance ( $p$-values) of differences in microbial composition between groups of OTUs (Anderson 2017; Lagkouvardos et al. 2017). Three biological replicates were analysed for all sampling time points with the exception of the enhanced ABT-100 yoghurt sample after five days of storage at $4{ }^{\circ} \mathrm{C}$, where only two biological replicates were analysed as no DNA could be recovered due to a methodological problem during DNA isolation in the third replicate.

\section{Results}

In this study, 16S rRNA gene sequencing was used to analyse the microbial diversity of reformulated (sweetness-enhanced) yoghurt samples compared with regular yoghurt that was prepared using two different commercial mixed strain yoghurt starter culture preparations. Statistical analysis of samples taken during fermentation and post-acidification storage demonstrated that there was no significant difference between the microbial composition of yoghurt produced with either 
sweetness-enhanced or regular milk. This was observed for both the traditional YoFlex ${ }^{\circledR}$ Premium 4.0 starter culture preparation containing $S$. thermophilus and $L b$. delbrueckii subsp. bulgaricus $(p=0.401)$ strains and the mild-tasting, probiotic ABT-100 culture preparation containing S. thermophilus, Lb. acidophilus and a Bifidobacterium sp. strains $(p=0.657)$.

In yoghurt samples produced with both the traditional and the probiotic yoghurt culture, the genera of lactic starter cultures dominated all samples by the end of the fermentation period at $43{ }^{\circ} \mathrm{C}$. The diversity of microorganisms present in the yoghurt samples differed significantly $(p=0.001)$ between samples taken directly after milk inoculation with starter cultures and samples taken following fermentation, once the $\mathrm{pH}$ had reached 4.5 and the samples were cooled. In the traditional yoghurt culture (Fig. 1), the starter Streptococcus strain grew rapidly during fermentation, reaching a relatively dominant species abundance in all samples (81-88\%) after fermentation. This was maintained during the 21-day storage period at $4{ }^{\circ} \mathrm{C}$. The relative abundance of Lactobacillus DNA sequences, which presumptively stemmed from the starter Lactobacillus strain in these samples, was between ca. $2-7 \%$ of the total read abundances following fermentation.

In yoghurt samples produced using the probiotic ABT-100 yoghurt starter culture preparation (Fig. 2), $16 \mathrm{~S}$ rRNA metagenomic analyses confirmed the roughly equivalent inoculation levels of Streptococcus and Bifidobacterium [ca. $10^{7} \mathrm{cfu} / \mathrm{mL}$ for both these species, as demonstrated by Luzzi et al. (2020)], showing a ca. $20-35 \%$ relative abundance of each bacterial species. The Lactobacillus component of the mixed starter culture was inoculated about $1 \log \mathrm{cfu} / \mathrm{mL}$ lower than Streptococcus and Bifidobacterium, and this was reflected by a relative bacterial abundance of only $1 \%$ in the metagenomic analysis of samples taken at inoculation. As a result of rapid growth of lactic acid bacteria during fermentation, an expected significant difference $(p=0.001)$ in microbial ecology, as determined by PERMANOVA analyses, was observed in samples taken before and after fermentation with the probiotic ABT-100 starter culture preparation. The abundance of bacteria of the Streptococcus genus, which presumptively stems from the starter culture, were measured at an abundance of $\sim 70 \%$ after fermentation (at the time point of cold storage) in comparison to the those of the presumptive starter Lactobacillus (3-7\%) and Bifidobacterium (15-17\%) strains. Furthermore, the microbial diversity in the probiotic ABT-100 culture differed significantly $(p=0.001)$ between the beginning of cold storage and after five days of storage, presumptively due to the growth of the acidophilic starter $L b$. acidophilus, further changing the relative abundances of all starter bacteria during storage. As post-acidification progressed, the relative abundance of probiotic $L b$. acidophilus and Bifidobacterium species was observed to increase to $31-40 \%$ and $11-26 \%$, respectively.

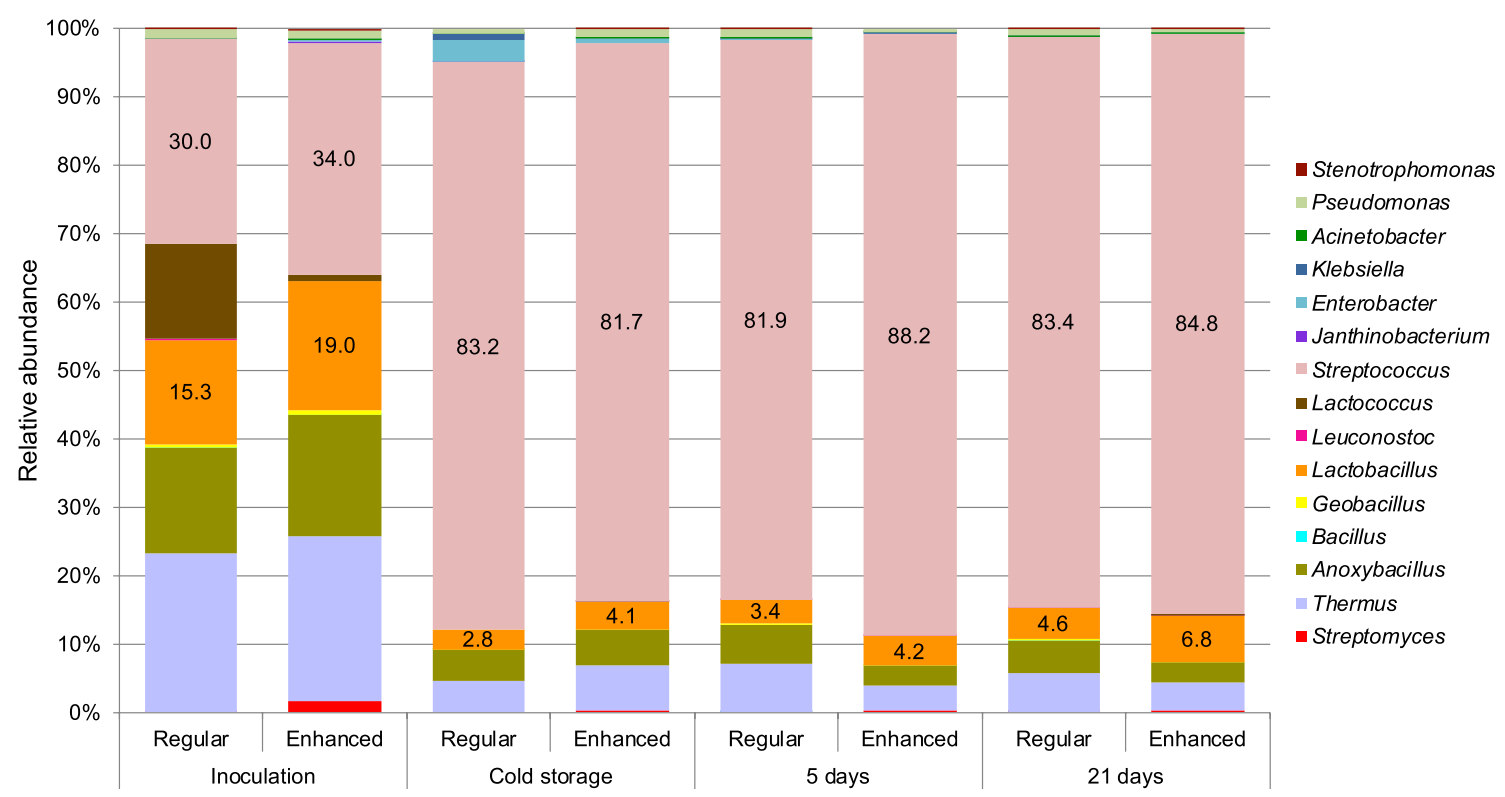

Fig. 1 Relative microbial abundance (\%) in yoghurt produced using regular and sweetness-enhanced (enhanced) milk using the traditional YoFlex ${ }^{\circledR}$ Premium 4.0 starter culture. The relative abundance of the starter culture genera (Streptococcus and Lactobacillus) are indicated 


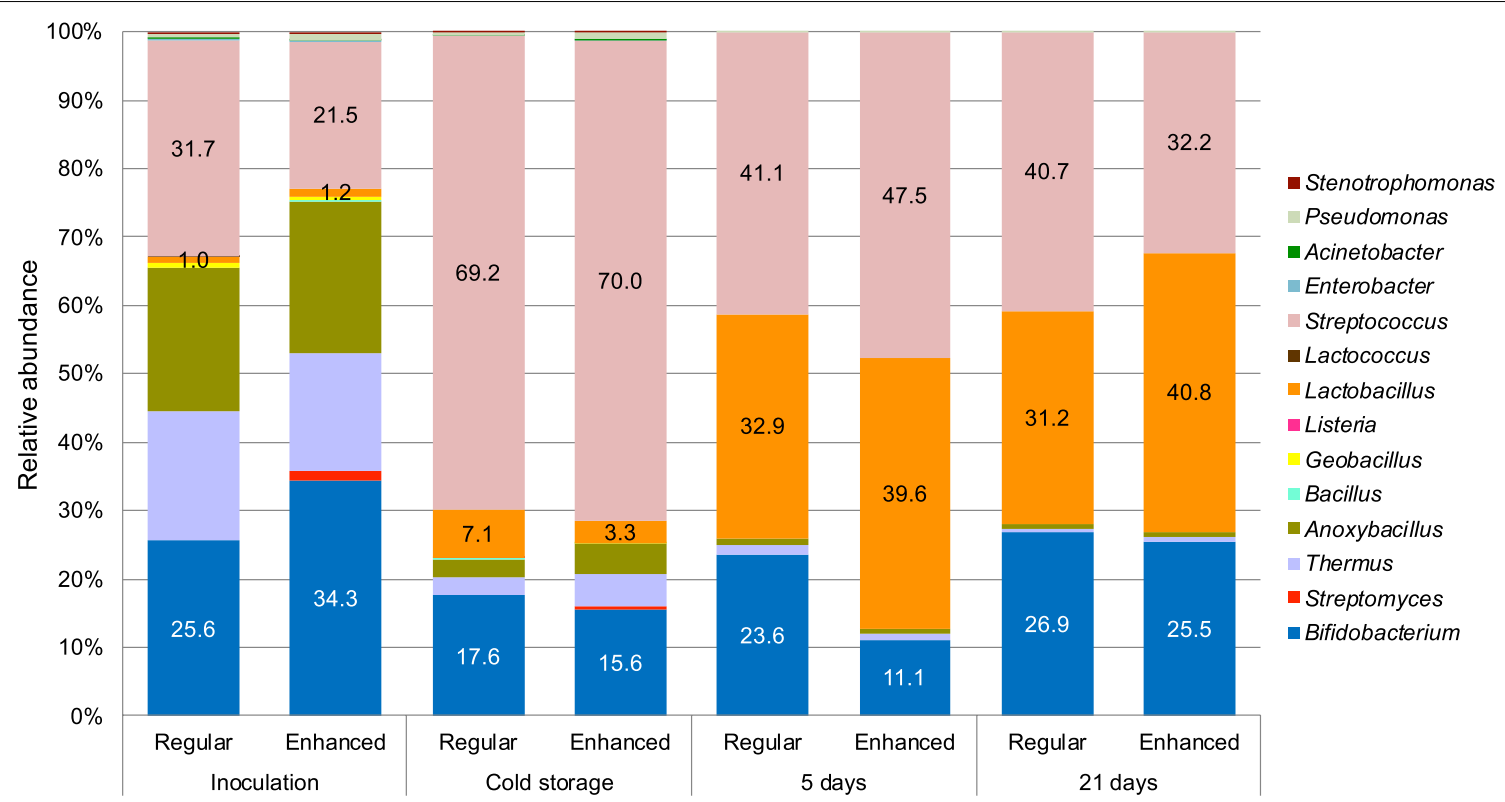

Fig. 2 The relative abundance (\%) of genera in yoghurt produced using sweetness-enhanced (enhanced) and regular milk using the probiotic ABT-100 culture. The relative abundances of the starter culture genera (Streptococcus, Lactobacillus and Bifidobacterium) are indicated

\section{Discussion}

Sweetness-enhanced yoghurt samples taken during fermentation and post-acidification storage were analysed using $16 \mathrm{~S}$ rRNA gene sequencing and statistical analyses demonstrated no significant difference between the microbial composition of this yoghurt compared to regular yoghurt. This held true for both yoghurt produced with the traditional YoFlex ${ }^{\circledR}$ Premium 4.0 starter culture preparation as well as the mild-tasting, probiotic ABT-100 culture preparation. The implemented starter culture lactic acid bacteria therefore seemed to ferment the sweetness-enhanced milk in an equal manner to regular milk, despite the altered carbohydrate composition (Luzzi et al. 2020), which results in the presence of the monosaccharides glucose, galactose and fructose being more readily available for bacterial growth in the milk matrix.

The genera of lactic starter cultures predominated the microbial composition of all samples after fermentation of the sweetness-enhanced and regular milk (when yoghurt samples were placed in cold storage), showing a significant difference at this time point compared to the microbial diversity measured at inoculation. This change in microbial ecology between samples taken directly after milk inoculation with starter cultures and those taken following the fermentation period appears to confirm the essential growth of starter cultures needed for both acidification of the matrix and protection against the growth of unwanted organisms, not to mention to provide the desired product characteristics (Vedamuthu 2006).

In all traditional yoghurt samples, the presumptive starter Streptococcus strain grew rapidly during fermentation and their relative abundance clearly dominated over the abundance of DNA sequences from the presumptive Lactobacillus starter strains (Fig. 1). As high throughput sequencing cannot resolve bacterial taxonomy to the species level, the Streptococcus and Lactobacillus sequences obtained were thus termed presumptive Streptococcus and Lactobacillus starter strains in this study. As previously demonstrated by Luzzi et al. (2020) using traditional microbiological methods, the starter Streptococcus strain was inoculated nearly $3 \log \mathrm{cfu} / \mathrm{mL}$ higher than the Lactobacillus strain in all yoghurt samples produced using this multiple-species traditional YoFlex ${ }^{\circledR}$ Premium 4.0 starter culture preparation. The high relative abundance of Streptococcus DNA sequences observed in the product samples is likely to have overshadowed the relative abundance of Lactobacillus sequences detected, making the latter appear to be only minimally present after fermentation (Gobbetti et al. 2015). A similar effect could be observed at cold storage in samples produced using the probiotic ABT-100 yoghurt starter culture preparation (Fig. 2), where the abundance of Streptococcus strains clearly dominated the presumptive stater Lactobacillus and Bifidobacterium strains after fermentation. In this probiotic yoghurt, 16S rRNA metagenomic analyses confirmed the similar inoculation levels of 
Streptococcus and Bifidobacterium strains for both these species, as determined by Luzzi et al. (2020) for these samples using traditional microbiological methods.

The culture-dependent viable counts of the starter bacteria measured in a parallel study in the same reformulated yoghurt samples as analysed in this study showed a typical and expected microbial growth and acidification progression in the YoFlex ${ }^{\circledR}$ Premium 4.0 starter culture for a traditional yoghurt starter culture (Luzzi et al. 2020). The ABT-100 culture displayed a decline in probiotic bacteria during storage, which is not uncommon in yoghurt, as a result of sensitivities of Lb. acidophilus and Bifidobacterium to the build-up of dissolved oxygen, organic acids and hydrogen peroxide produced by lactic acid bacterial metabolism (Gilliland and Speck 1977; Shah 2000; Ng et al. 2011). The results of the current $16 \mathrm{~S}$ rRNA sequencing study therefore confirm the culturedependent results presented previously by Luzzi et al. (2020).

The analysis of bacterial DNA from samples containing a diverse microbial population, such as can be found in fermented dairy products, does not allow for differentiation of DNA isolated from living, injured or dead cells. As the DNA from the entire yoghurt samples was isolated and sequenced in this study, it is impossible to distinguish the microbial abundance of live bacterial populations from dead cells in these samples. Hence, the increase in relative microbial abundance observed during storage of probiotic yoghurt produced with the ABT-100 culture, despite a decline in viable counts of Lactobacillus and Bifidobacterium species measured by Luzzi et al. (2020) in these samples, can be explained by the detection of DNA from the viable cells as well as from bacteria that were injured or died during yoghurt storage. In future studies, such confounding could be avoided by applying DNA-staining of dead or injured cells, for example using propidium monoazide or ethidium monoazide, and subsequent elimination of stained cells from the microbial sample, prior to DNA sequencing analysis (Rudi et al. 2005; Erkus et al. 2016).

The microbial diversity observed after inoculation of the milk for yoghurt production with both starter culture preparations displays a wide range of bacterial genera, which decreases after fermentation and during storage. This initial diversity probably stemmed from the microorganisms present in raw milk prior to milk pasteurisation and subsequent yoghurt manufacture. The microbiota of raw milk is known to be quite diverse, yet the pasteurisation process of milk prior to yoghurt production aims to inactivate the majority of unwanted spoilage and potentially pathogenic bacteria (Quigley et al. 2013). However, the DNA of these eliminated bacteria is still present in the milk and hence is also detected by the $16 \mathrm{~S}$ rRNA metagenomics sequencing approach used in this study. Due to the rapid growth of starter culture bacteria during fermentation, the relative abundance of the DNA presumptively stemming from the starter culture bacteria dominated the samples at and after the time point of cold storage of the yoghurt after fermentation. Hence, the relative DNA abundances from non-living raw milk microbiota should not be strongly represented in relative abundance calculations as storage progresses. The quick dominance of starter lactic acid bacteria observed by the end of yoghurt fermentation in this study contributed to inhibiting the growth of any spoilage or potentially pathogenic bacteria, as shown using culture-dependent determinations by Luzzi et al. (2020), presumably through the creation of acidic conditions (Vedamuthu 2006).

In this study, a low abundance of Pseudomonas and other Proteobacteria $(<5 \%)$ was detected in all yoghurt samples produced with sweetness-enhanced and regular milk. Contrary to this, Zalewska et al. (2018) observed a corresponding high abundance of Firmicutes (e.g. Lactobacillales) but also of Proteobacteria (e.g. Pseudomonadales) in yoghurt sampled immediately after fermentation and an increase in Proteobacteria by the end of a 28-day storage period. However, the diverse microbial composition measured in (raw) milk samples, including Lactobacillales as well as Pseudomonadales, greatly depends on the farm and processing facility, as demonstrated in earlier studies by Quigley et al. (2013). Hence, comparison of microbial abundances between studies should only be made with caution. Furthermore, the opportunities for secondary contamination with Pseudomonadales after pasteurisation may be higher in a commercial milk processing environment than in pilot plant production as was the case in this study, as the milk holding tanks and processing equipment provide ample sources of contaminating bacteria.

In conclusion, the current study demonstrated that using sweetness-enhanced milk for yoghurt production did not affect the microbial ecology of the reformulated yoghurt samples in comparison to regular yoghurt samples. In both yoghurt samples produced using a traditional as well as a probiotic yoghurt starter culture preparation, the microbial biodiversity did not change between sweetness-enhanced and regular yoghurt at all sampling time points despite the altered carbohydrate composition of the milk matrix. From a microbiological perspective, this reformulation approach does not affect the essential growth of starter lactic acid bacteria needed to achieve the desired product characteristics of yoghurt, nor does it allow for a greater growth potential for spoilage or potentially pathogenic bacteria. 


\section{Acknowledgements}

This research project was funded by the Federal Ministry of Food and Agriculture (BMEL) based on a decision of the Parliament of the Federal Republic of Germany to provide an innovation support programme managed by the Federal Office for Agriculture and Food (BLE). The authors would like to thank Jennifer Grundmann for support with microbiological analysis and Adrian Prager for support with 165 rRNA gene high throughput sequencing.

\section{Authors' contributions}

GL conducted experiments, performed data analysis, interpreted data, wrote the original manuscript and created the figures. EB conducted experiments and performed data analysis and interpretation. JF and CF conceptualised the study and acquired funding. CF also supervised the study and was involved in data interpretation. All authors read and approved the final manuscript.

\section{Funding}

Open access funding provided by Projekt DEAL. This study was funded by the German Federal Ministry of Food and Agriculture (Grant Number 2819107616).

\section{Availability of data and materials}

The $16 \mathrm{~S}$ rRNA gene sequencing raw data have been deposited in the Sequence Read Archive (SRA) with links to BioProject accession number PRJNA630675 in the NCBI BioProject database (https://www.ncbi.nlm.nih.gov/ bioproject/).

\section{Ethics approval and consent to participate}

Not applicable.

\section{Consent for publication}

Not applicable.

\section{Competing interests}

The authors declare that they have no conflict of interest/competing interests.

\section{Author details}

1 Department of Microbiology and Biotechnology, Max Rubner-Institut, Hermann-Weigmann-Str. 1, 24103 Kiel, Germany. ${ }^{2}$ Department of Safety and Quality of Milk and Fish Products, Max Rubner-Institut, Hermann-Weigmann-Str. 1, 24103 Kiel, Germany.

Received: 17 May 2020 Accepted: 18 July 2020

Published online: 25 July 2020

\section{References}

Alexy U, Sichert-Hellert W, Kersting M (2003) Associations between intake of added sugars and intakes of nutrients and food groups in the diets of German children and adolescents. Br J Nutr 90:441-447. https://doi. org/10.1079/bjn2003904

Anderson MJ (2017) Permutational multivariate analysis of variance (PERMANOVA). Wiley, New York, pp 1-15

Chandan RC (2006) Milk composition, physical and processing characteristics. In: Chandan RC, White CH, Kilara A, Hui YH (eds) Manufacturing Yogurt and Fermented Milks, 1st edn. Blackwell Publishing, Ames, pp 17-39

Cole JR, Wang Q, Fish JA, Chai B, McGarrell DM, Sun Y, Brown CT, Porras-Alfaro A, Kuske CR, Tiedje JM (2014) Ribosomal database project: data and tools for high throughput rRNA analysis. Nucleic Acids Res 42:D633-D642. https://doi.org/10.1093/nar/gkt1244

Edgar RC (2013) UPARSE: highly accurate OTU sequences from microbial amplicon reads. Nat Methods 10:996-998. https://doi.org/10.1038/nmeth .2604

Edgar RC (2010) Search and clustering orders of magnitude faster than BLAST. Bioinformatics 26:2460-2461. https://doi.org/10.1093/bioinformatics/ btq461

Erkus O, de Jager VCL, Geene RTCM, van Alen-Boerrigter I, Hazelwood L, van Hijum SAFT, Kleerebezem M, Smid EJ (2016) Use of propidium monoazide for selective profiling of viable microbial cells during Gouda cheese ripening. Int J Food Microbiol 228:1-9. https://doi.org/10.1016/j. ijfoodmicro.2016.03.027

Gilliland SE, Speck ML (1977) Instability of Lactobacillus acidophilus in yogurt. J Dairy Sci 60:1394-1398. https://doi.org/10.3168/jds.S0022-0302(77)84042 $-3$

Gobbetti M, De Angelis M, Di Cagno R, Mancini L, Fox PF (2015) Pros and cons for using non-starter lactic acid bacteria (NSLAB) as secondary/adjunct starters for cheese ripening. Trends Food Sci Technol 45:167-178. https:// doi.org/10.1016/j.tifs.2015.07.016

Harju M, Kallioinen H, Tossavainen O (2012) Lactose hydrolysis and other conversions in dairy products: technological aspects. Int Dairy J 22:104-109. https://doi.org/10.1016/j.idairyj.2011.09.011

Klindworth A, Pruesse E, Schweer T, Peplies J, Quast C, Horn M, Glöckner FO (2013) Evaluation of general 16S ribosomal RNA gene PCR primers for classical and next-generation sequencing-based diversity studies. Nucleic Acids Res 41:1-11. https://doi.org/10.1093/nar/gks808

Lagkouvardos I, Fischer S, Kumar N, Clavel T (2017) Rhea: a transparent and modular R pipeline for microbial profiling based on 165 rRNA gene amplicons. Peer J 5:e2836. https://doi.org/10.7717/peeri.2836

Lagkouvardos I, Joseph D, Kapfhammer M, Giritli S, Horn M, Haller D, Clavel T (2016) IMNGS: a comprehensive open resource of processed 16S rRNA microbial profiles for ecology and diversity studies. Sci Rep 6:33721. https ://doi.org/10.1038/srep33721

Lorenzen PC, Breiter J, Clawin-Rädecker I, Dau A (2013) A novel bi-enzymatic system for lactose conversion. Int J Food Sci Technol 48:1396-1403. https ://doi.org/10.1111/ijfs.12101

Luzzi G, Steffens M, Clawin-Rädecker I, Hoffmann W, Franz CMAP, Fritsche J, Lorenzen PC (2020) Enhancing the sweetening power of lactose by enzymatic modification in the reformulation of dairy products. Int J Dairy Technol. https://doi.org/10.1111/1471-0307.12681

Max Rubner-Institut (2008) Nationale Verzehrsstudie II, Ergebnisbericht, Teil 2. https://www.bmel.de/SharedDocs/Downloads/Ernaehrung/NVS_Ergeb nisberichtTeil2.pdf?_blob=publicationFile. Accessed 25 Sept 2018

Max Rubner-Institut (2016) Reformulierung von verarbeiteten Lebensmitteln: Bewertungen und Empfehlungen zur Reduktion des Zuckergehalts. https ://www.mri.bund.de/fileadmin/MRI/Themen/Reformulierung/Reformulie rung_Thema-Zucker.pdf. Accessed 10 Jun 2019

$\mathrm{Ng}$ EW, Yeung M, Tong PS (2011) Effects of yogurt starter cultures on the survival of Lactobacillus acidophilus. Int J Food Microbiol 145:169-175. https ://doi.org/10.1016/j.ijfoodmicro.2010.12.006

Pruesse E, Peplies J, Glöckner FO (2012) SINA: accurate high-throughput multiple sequence alignment of ribosomal RNA genes. Bioinformatics 28:1823-1829. https://doi.org/10.1093/bioinformatics/bts252

Quigley L, McCarthy R, O'Sullivan O, Beresford TP, Fitzgerald GF, Ross RP, Stanton C, Cotter PD (2013) The microbial content of raw and pasteurized cow milk as determined by molecular approaches. J Dairy Sci 96:49284937. https://doi.org/10.3168/jds.2013-6688

Rudi K, Moen B, Drømtorp SM, Holck AL (2005) Use of ethidium monoazide and PCR in combintion for quantification of viable and dead cells in complex samples. Appl Environ Microbiol 71:1018-1024. https://doi. org/10.1128/AEM.71.2.1018

Shah NP (2000) Probiotic bacteria: selective enumeration and survival in dairy foods. J Dairy Sci 83:894-907. https://doi.org/10.3168/jds.S0022 $-0302(00) 74953-8$

Vedamuthu ER (2006) Starter cultures for yogurt and fermented milks. In: Chandan RC, White CH, Kilara A, Hui YH (eds) Manufacturing yogurt and fermented milks, 1st edn. Blackwell Publishing, Ames, pp 89-115

Zalewska B, Kaevska M, Slana I (2018) Sequence analysis of changes in microbial composition in different milk products during fermentation and storage. Curr Microbiol 75:202-205. https://doi.org/10.1007/s0028 $4-017-1366-z$

\section{Publisher's Note}

Springer Nature remains neutral with regard to jurisdictional claims in published maps and institutional affiliations. 